\title{
A REVIEW ON THE MICROSTRUCTURE OF INTERFACES IN REINFORCED CONCRETE AND ITS EFFECT ON THE BOND STRENGTH
}

\author{
Fadhilah Muslim $^{1 *}$ \\ ${ }^{1}$ Department of Civil Engineering, Faculty of Engineering, Universitas Indonesia, Depok 16424
}

(Received: January 2020 / Revised: February 2020 / Accepted: May 2020)

\begin{abstract}
Studies on the microstructural characteristics of the interfaces in reinforced concrete and its effect on the mechanical properties i.e. bond strength have been conducted for many years, even since 1956. However, a summary of existing knowledge and findings related to the different types of interfaces is still lacking. Therefore, this paper reviews the characteristic of different types of interfaces in reinforced concrete including those between: a) aggregate particles and cement paste, i.e. the interfacial transition zone (ITZ); b) steel reinforcing bars and concrete; and c) old (substrate) and new concrete (repair materials). The aim of this review is to show how similar and different the characteristics of interfaces in reinforced concrete. Such information is important for understanding the properties and durability as well as how it might affect the long-term performance of concrete structures.
\end{abstract}

Keywords: Microstructure; Bond strength; Aggregate-cement paste interface; Steel-concrete interface; Old-to-new concrete interface

\section{INTRODUCTION}

Jacques Farran first discussed the term of interfaces in concrete in 1956, as mentioned in the RILEM report "Interfacial transition zone in concrete" (Farran, 1996). It was used to describe the interfacial zone between the aggregate and cement paste known as "transition aureole", and hereafter referred to as the interfacial transition zone (ITZ). Since then, even today, many studies have been conducted to figure out the nature, characteristics, and influences of the ITZ in concrete on concrete properties. Other types of interfaces such as steel-concrete interface (SCI) and new-to-old concrete interface also exist, and the microstructural characteristics and mechanical properties of these interfacial zones are reviewed here.

\section{FORMATION MECHANISM AND MICROSTRUCTURE}

\subsection{Aggregate-cement paste interface}

According to Scrivener et al. (2004), the ITZ between aggregate and cement paste is a particularly important interface in reinforced concrete. This refers to the cement paste region adjacent to every aggregate particle surface, which has a microstructure that is disrupted by the presence of the aggregate itself. Zimbelmann (1987) and Bentur and Odler (1996) found that the formation of the ITZ is mainly caused by micro-bleeding and wall effects. 
Bleeding occurs when the mixed water separates from other denser constituents and accumulates on the surface of aggregate particles or becomes trapped under aggregate particles. In contrast, the wall effect refers to the difficulty of packing small aggregate particles close to the surfaces of larger particles. In concrete, cement particles are unable to effectively fill the space adjacent to aggregate particles. Both effects create a high-water content and low cement content, therefore an effectively larger water/cement ratio around the aggregate surface compared to the "bulk" paste region farther away. Thus, the ITZ tends to be a highly porous zone that contains less anhydrous cement content, but rich in $\mathrm{Ca}(\mathrm{OH})_{2}$ due to preferential precipitation. Apart from bleeding and wall effects, the higher porosity at the ITZ is also caused by the one-sided growth effect, as proposed by Garboczi and Bentz (1991). In the region of bulk-paste farther away from the aggregate surface, hydration products are able to grow into from all directions. But there is no growth from the direction of the aggregate closest to the aggregate surface since the aggregate is non-reactive, therefore the space-filling resulting from hydration is less prominent at the ITZ. The main mechanisms forming the ITZ are shown in Figure 1.

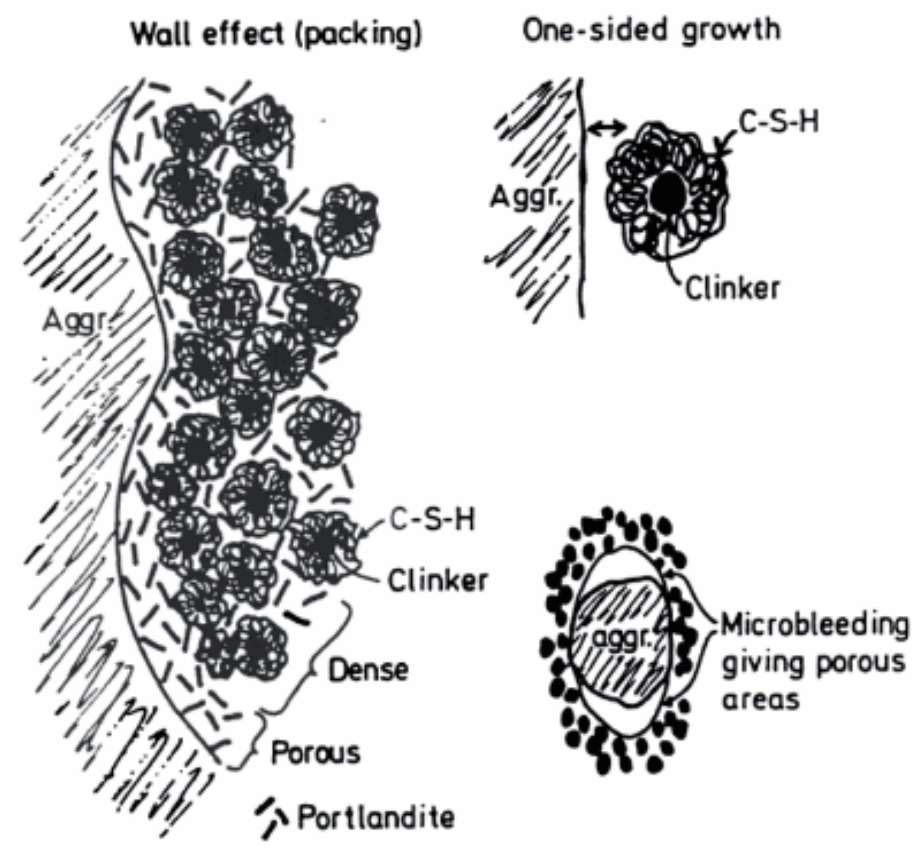

Figure 1. Schematic showing the formation of ITZ between aggregate and cement paste Source: (Kjellsen et al., 1998)

Although the mechanisms forming the ITZ are approximately the same, the thickness of the ITZ is not uniformly exhibited in different concrete mixes and even within the same concrete mix. Studies have shown that the ITZ thickness varies between different aggregate particles and on different parts of the same aggregate. It also depends on the cement size and type, water-cement ratio, and the aggregate size used (Breton et al., 1993; Monteiro, Gjorv, et al., 1985). Several techniques have been used to examine and to quantitatively characterize the ITZ. These include scanning electron microscope in the backscattered electron (BSE) imaging mode (S. Diamond \& Huang, 2001; Sidney Diamond, 2004; K. L. Scrivener et al., 1988), mercury intrusion porosimetry (MIP) (Snyder et al., 1992), X-ray diffraction (XRD) (Tasong et al., 1999), laser scanning confocal microscopy (LSCM) (Zampini et al., 1995), and nanoindentation testing (Mondai et al., 2008).

For example, Hoshino (1989) found ITZ widths ranging from approximately 10 to $100 \mu \mathrm{m}$, with the highest porosity forming adjacent to the bottom surface of aggregate particles and the 
lowest porosity near the top surface, relative to casting direction. Monteiro et al. (1985) and Scrivener et al. (2004) estimated the effective ITZ thickness to be approximately 20 to $50 \mu \mathrm{m}$, with a significant difference in characteristics from the bulk paste occurring within the first $20 \mu \mathrm{m}$ from the aggregate particle. This is the region where the microstructure and hydration products formed are very different from the bulk cement paste. The microstructure of the ITZ as illustrated by Zimbelmann (1985) is shown in Figure 2.

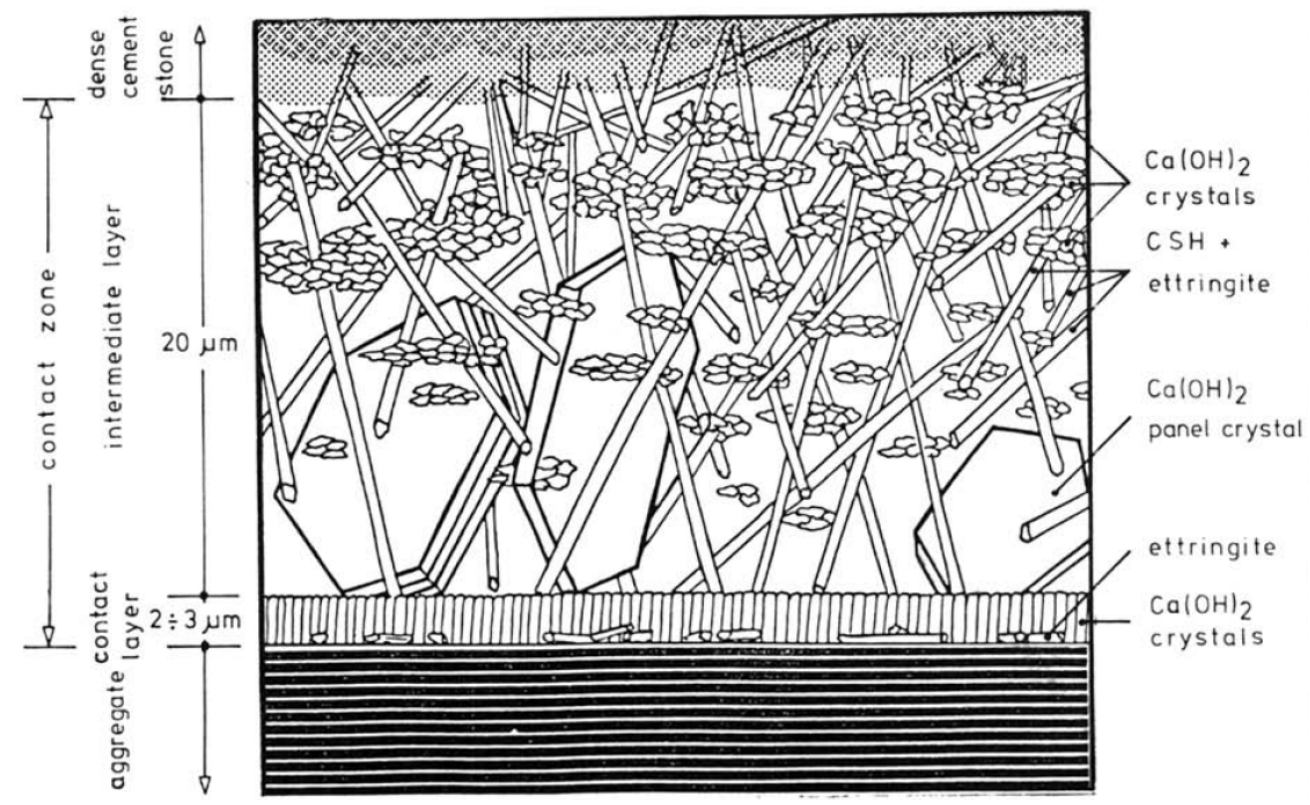

Figure 2. Model of the ITZ between cement paste and aggregate particle

Source: (Zimbelmann, 1985)

Generally, the use of ultrafine reactive supplementary cementitious materials to replace Portland cement will improve particle packing and hence the characteristics of the ITZ. For example, Cheng-Yi and Feldman (1985); Bentur and Cohen (1987); Cohen et al. (1994) showed that by incorporating silica fume in the mortar mix, the microstructure of the ITZ becomes much denser and homogeneous, without the presence of large $\mathrm{CH}$ precipitates. The level of porosity at the ITZ becomes similar to that of the bulk paste, thereby improving the pasteaggregate bond. Bentz and Garboczi (1991) also found that the incorporation of fly ash in the mix reduces the volume fraction of $\mathrm{CH}$ and increases the amount of the total C-S-H at the ITZ, relative to that present in the bulk paste. Larbi (1993) described that the inclusion of fly ash, metakaolin, silica fume, or ground-granulated blast-furnace slag in mortar mixes modifies the interface to become denser with no $\mathrm{CH}$ crystals.

\subsection{Steel-concrete interface}

It is well-established that concrete is strong in compression but very weak in tension. Therefore, steel reinforcement is embedded in structural concrete to form a composite material i.e. reinforced concrete, that can withstand not only compression but also bending and tension. The presence of steel leads to the formation of an interfacial zone between steel and concrete. Similar to the aggregate-cement paste interface, the steel-concrete interface plays a crucial role in determining the performance of reinforced concrete. The formation mechanism and microstructure of the steel-concrete interface are considered to be similar to that of the aggregate-paste ITZ in terms of porosity and portlandite distribution, which is mainly attributed 
to the ineffective packing of cement particles due to wall-effects (Al Khalaf \& Page, 1979; Horne et al., 2007; Monteiro, Maso, et al., 1985; Yue \& Shuguang, 2001).

However, differences between the aggregate-paste interface and the steel-concrete interface have been noted. For example, Otsuki et al. (1998) noted that gaps tend to form at the steelconcrete interface as a result of vibration. It was observed that the vibration can lead to higher local water content and less efficient packing around the steel. Khayat (1998) explained that the voids formed under horizontal rebar were due to bleeding, aggregate segregation, or surface settlement (bulk shrinkage) of fresh concrete. Fresh concrete consists of an unstable dispersion of cement paste and aggregate particles. When the bleeding water rises towards the upper concrete surface, some of the bleed water can become trapped under various obstacles for example steel reinforcement. It causes an increase in the local $\mathrm{w} / \mathrm{c}$ ratio under the rebar, thus increasing the porosity. The settlement of aggregates at the same time can also lead to a minute separation between the lower area of reinforcement and concrete leaving an air void. A study by Horne et al. (2007) also observed that the underside of horizontal rebars had gaps or much higher porosity, and no $\mathrm{CH}$ within the first $40 \mu \mathrm{m}$ compared to the topside and around vertical rebar as shown in Figure 3. A review paper by Angst et al. (2017) presented a schematic illustration to describe the characteristics of the steel-concrete interface (Figure 4).
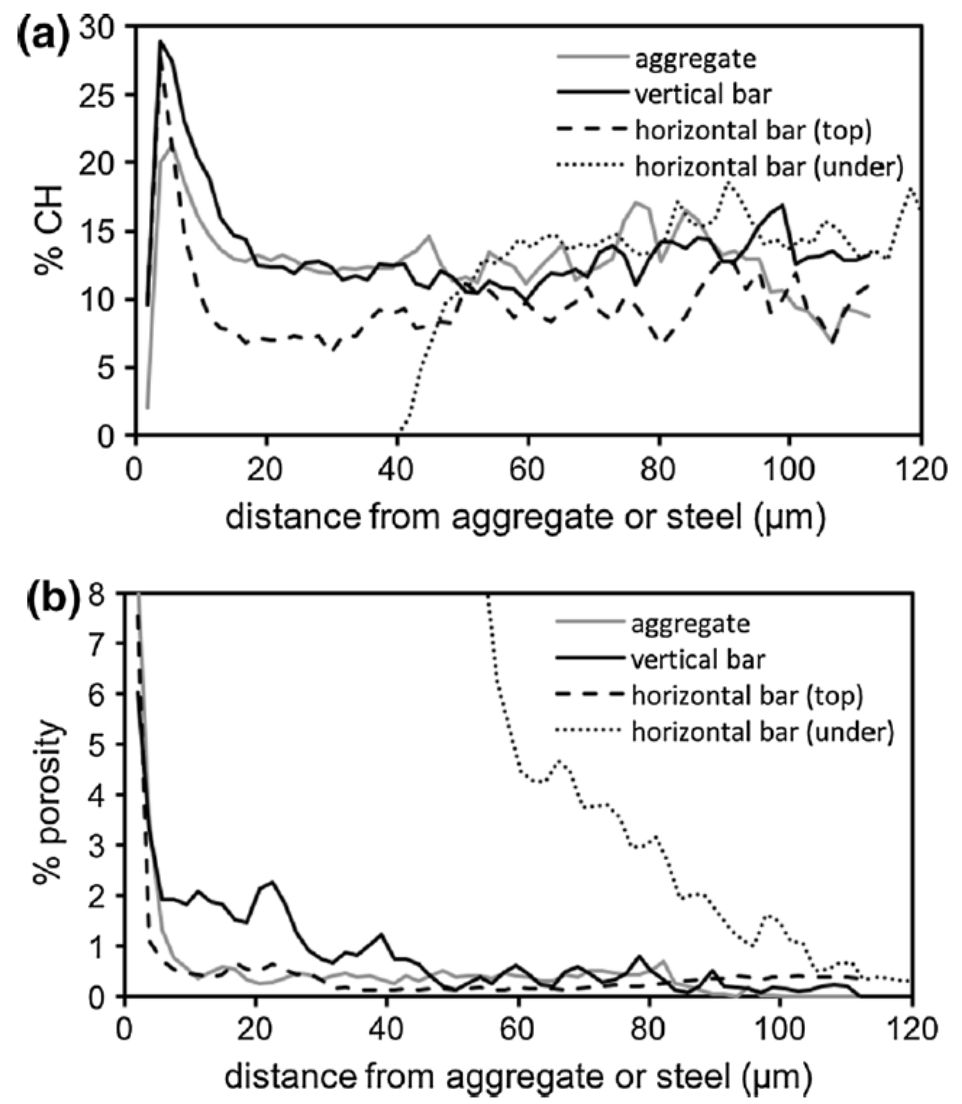

Figure 3. Typical of microstructural gradients of (a) $\mathrm{CH}$ (Portlandite) and (b) porosity at the steel-concrete interface

Source: (Angst et al., 2017; Horne et al., 2007) 


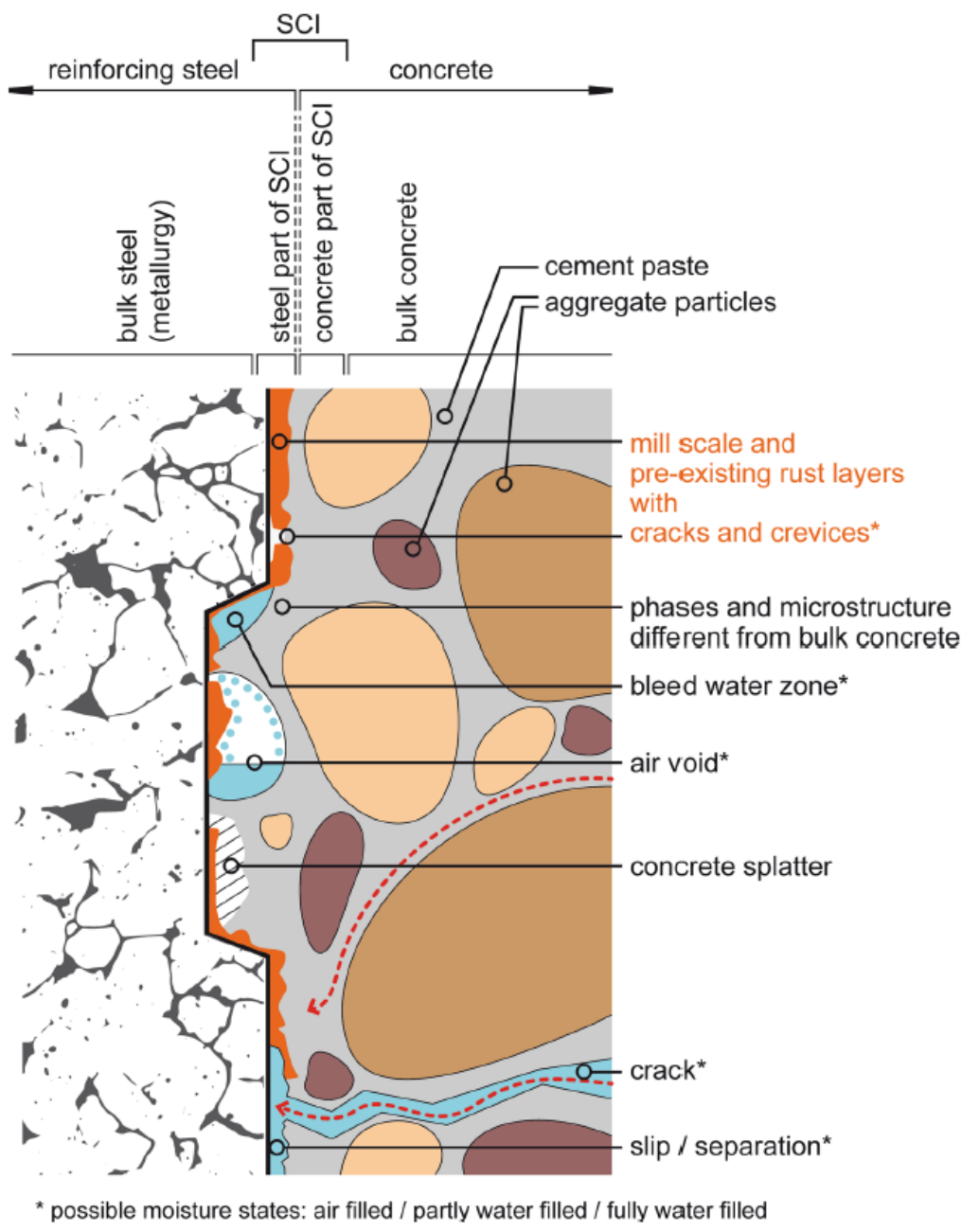

Figure 4. Schematic illustration of the steel-concrete interface. Red dashed lines illustrate preferential pathways for chloride ingress; blue dots indicate adsorbed water

Source: (Angst et al., 2017)

\subsection{New-to-old concrete interface}

An interface forms when new concrete is cast against old concrete (substrate). Such interfaces are common in construction, for example: between two different concrete elements, concrete overlays used for repair and strengthening of concrete members or composite elements consisting of concrete precast. According to Pigeon and Saucier (1992); Carles-Gibergeus et al. (1993) and Delagrave et al. (1997), the interface between the old (substrate) and the new concrete (repair material) displays similar characteristics to the interface between aggregate and cement paste. This has been attributed to the wall-effect that creates a weak link in the repaired material. Further studies by Momayez et al. (2004) and Lukovic et al. (2014) observed that the weak link leads to a high probability of cracking.

Xie et al. (2002) proposed a model of the interfacial microstructure between new and old concrete. This is shown in Figure 5. The first layer located on the old concrete surface is called a penetration layer. This mainly consists of C-S-H and some amount of Aft (ettringite) or $\mathrm{Ca}(\mathrm{OH})_{2}$ (portlandite) and is assumed to have no harmful influence on interface bond strength. The second layer was defined as a boundary between fresh and old concrete, also known as the strongly-affected layer. This layer is not only rich in $\mathrm{Ca}(\mathrm{OH})_{2}$ and needle-shaped ettringite (Aft) crystals, but also contains a large number of voids and cracks. This layer is the weakest layer of the interfacial zone. The third layer is known as the weakly-affected layer, which is located 
within the new concrete. It has a similar microstructure as the new concrete but less C-S-H, therefore, its strength is better than the second layer. The thickness of the third layer depends on the nature and characteristics of the new concrete and bonding agent.

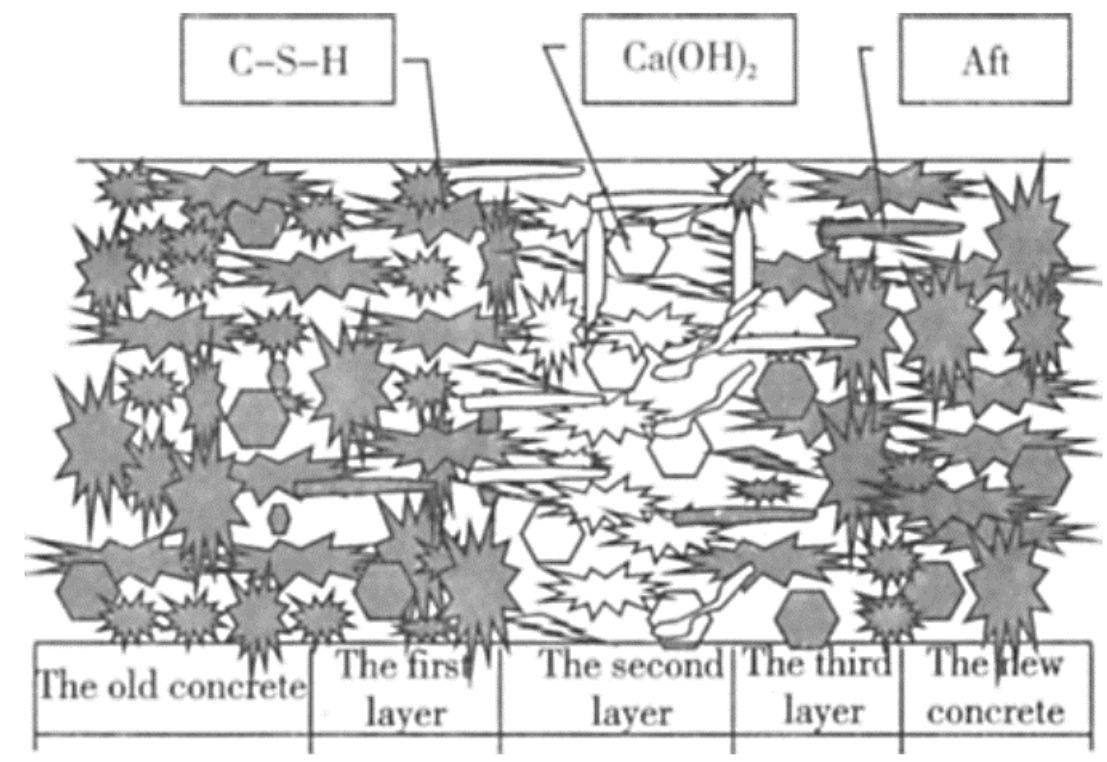

Figure 5. Schematic showing the proposed microstructure of the old-new concrete interface. The second layer defined as a boundary between fresh and old concrete is the weakest layer of the interfacial zone

Source: (Xie et al., 2002)

\section{EFFECT OF INTERFACES ON BOND STRENGTH}

\subsection{Aggregate-paste bond strength}

The ITZ is generally regarded as a weak link in concrete influencing its mechanical performance and is responsible for limiting some of the basic strength properties of concrete. This is because the bond strength between the aggregate-cement paste ITZ is much lower than the strength of either the aggregate particles or cement paste. Hsu and Slate (1963) investigated four types of rock (sandstone, granite, New York limestone, Indiana limestone) containing different moisture contents to investigate the tensile bond strength between the aggregate and cement paste. Three different surface roughness (naturally-fractured, saw-cut, and polished surface) were used for each rock. They observed that the cement paste-aggregate tensile bond strength was about 41 to $91 \%$ of the paste bond strength depending on the type and surface roughness of the aggregate and w/c ratio. A rougher surface and lower w/c ratio produced higher bond strengths. Bentur and Cohen (1987) showed that by using silica fume, an increase in concrete strength in the order of $25-30 \%$ over plain cement concrete can be achieved, without any corresponding strength increase in the paste sample. Ping and Beaudoin (1992) also found that the aggregate-paste bond strength depends on the thickness of the water layer on the aggregate surface and w/c ratio. Therefore, in order to increase bond strength, it is necessary to decrease the thickness of the water layer at the beginning of the mixing and w/c ratio. However, this finding was based on numerical simulations only, and no experiments were performed to prove this argument.

\subsection{Steel-concrete bond strength}

The bond between steel and concrete is significantly important in reinforced concrete structures because without any bond, the steel is completely ineffective and does not contribute to the flexural resistance of the structure. The bond depends on chemical adhesion, steel-concrete friction, and hardened concrete properties. The microstructural characteristics of the interface 
between steel and concrete also greatly affect the interface bond strength. Soylev and Francois (2003) and Castel et al. (2006) investigated the presence of defects (e.g. voids) at the underside of the horizontal rebar as shown in Figure 6. The authors found that such defects decrease the bond strength between the steel rebar and concrete.

As described in Section 2.1, the addition of supplementary cementitious materials i.e. silica fume in concrete can also reduce both the porosity and thickness of the interfacial zone and hence increase the pull-out strength between steel and concrete (Gjorv et al., 1990). This is due to a decrease in the amount of bleed water accumulated on the interface during casting and the number of $\mathrm{CH}$ deposits, as well as densification of the interface because of the pozzolanic reaction between $\mathrm{CH}$ and SF. Li et al. (1998) conducted a study on the enhancement of steelconcrete bond properties. Several methods were investigated including matrix modification by adding 1 or $2 \%$ (by weight of cement) of polyvinyl alcohol (PVA) powder into the concrete mix and surface modifications by coating the steel surface with cement, cement plus silica fume, and cement plus PVA. The mechanical properties of the interface were evaluated by push-out tests, scanning electron microscopy (SEM) and microhardness measurement. The results showed that such treatment methods reduced the porosity at the interface and increased the interfacial microhardness. However, no explanation was provided for this.

Surface treatments such as sand-blasting, water immersion, and ozone treatment have also been found to improve mechanical interlocking between steel and concrete, thus enhancing the interface (Chung, 2001). Sand-blasting results in roughening and cleaning the steel surface by removing rust and other contaminants on the surface. Water immersion involves immersing the steel in the water at room temperature for two days causing the formation of a black oxide layer on the steel surface. Ozone treatment involves exposing the steel to ozone gas for 20 minutes at $160^{\circ} \mathrm{C}$, followed by drying at high-temperature $\left(110^{\circ} \mathrm{C}\right)$ for another 50 minutes. This causes the formation of a dark grey oxide layer on the surface. The results showed that all the treatments increased bond strength, however ozone treatment produced the highest bond strength compared to sand-blasting and water immersion.

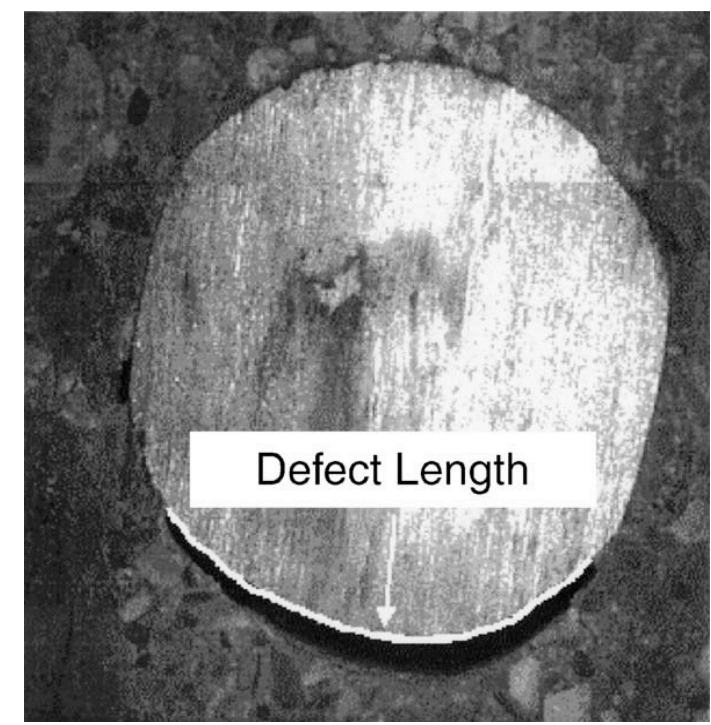

Figure 6. Defects at the steel-concrete interface

Source: (Soylev \& François, 2003) 


\subsection{New-to-old concrete bond strength}

According to Emberson and Mays (1990), repair materials for concrete structures can be categorized into three groups: resinous materials (i.e. epoxy mortar), polymer-modified cementitious materials (i.e. SBR modified), and conventional cementitious materials (i.e. $\mathrm{OPC} /$ sand mortar). Conventional cementitious materials such as mortars and concretes are often used, and they are considered the best option as repair materials because of the compatibility with the damaged concrete. Also, they are easy to be applied, placed, and cured, and are costeffective.

A successful repair is considered to be achieved when the repaired concrete shows uniform performance and behaves as a monolithic system with the substrate (old concrete). There are two crucial criteria for achieving decent performance and durability of the repair. The repair materials should be appropriate and compatible with the concrete substrates in terms of the chemical, physical and electrochemical properties, and have sufficient bond strength to enable the uniform transfer of stresses (Emmons \& Vaysburd, 1994; Morgan, 1996).

British Standard defines bond as the adhesion of the applied repair material to the old concrete (concrete substrate). According to Courard (2000), adhesion force and moisture transport are two main parameters that affect bond strength and its development at the interface between the new and old concrete. Adhesion force covers at least three types of bond: a chemical bond which is the result of chemical reactions that occur between the old and new concrete, mechanical bond which is related to the interpenetration of the new concrete into the roughness and porosity of the old concrete resulting in mechanical interlocking, and a physical bond associated with the Van der Waals and surface tension forces. Moisture transport is caused by the differences in the moisture content between new and old concrete. Water will move from areas of higher concentration to areas of lower concentration. In other words, unsaturated old concrete will absorb the water from fresh concrete by capillary suction. The absorption rate of the old concrete is mainly influenced by its initial moisture content and surface porosity.

The interface bond strength is influenced by at least three factors: (i) the properties of the old concrete and its surface (moisture content and roughness); (ii) the properties of the new concrete and its ability to adhere to the old concrete; and (iii) environmental conditions. Some studies have been conducted to understand the factors that influence bond strength. These have included substrate surface roughness (Beushausen \& Alexander, 2008; Júlio et al., 2004; Morgan, 1996; Tayeh et al., 2013), substrate moisture content (Carles-Gibergues et al., 1993; Morgan, 1996; Wall \& Shrive, 1988), and the properties of substrate concrete and repair materials (Beushausen \& Alexander, 2008; Carles-Gibergues et al., 1993; S. Diamond \& Huang, 2001; Hassan et al., 2001; Júlio et al., 2006; Tayeh et al., 2013). Among these, the surface roughness is considered as a major factor that contributes to bond strength.

A range of tests has been developed in the laboratory to evaluate bond strength (Beushausen \& Alexander, 2008; Momayez et al., 2004). They are divided into several categories. The first category is based on applying tensile stress, either via a direct tension, pull-off test (Figure 7a), and tensile splitting (Figure 2.7b). The most commonly used test methods under this category are the tensile pull-off test and the splitting test. In the tensile splitting test, a circular or prism or square cross-section is placed under longitudinal compressive loading (Figure 7b). Tensile stresses cause failure and divide the specimen into two parts. The second category is based on applying shear stress and is referred to as a direct shear method. This consists of L-shaped and direct shear tests (Figure 7c). The third category is based on a combination of compression and shear. The slant shear test is the most widely used in this category (Figure $2.7 \mathrm{~d}$ ). The slant shear test uses a cylindrical or a square prism sample made of two identical halves bonded at 
$30^{\circ}$ and tested under axial compression (Figure 7d). During loading, the interface is under shear and compressive stresses.

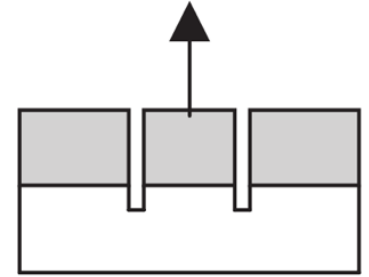

(a) Pull-off test

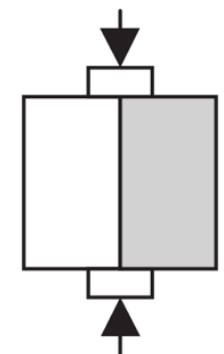

(b) Splittingtensile test

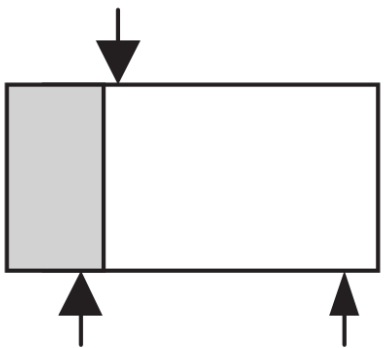

(c) Direct shear test

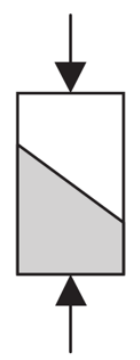

(d) Slant shear test

Figure 7. Schematic of various test methods to determine interface bond strength

Source: (Beushausen \& Alexander, 2008)

\section{CONCLUSION}

The interfacial characteristics between aggregate particles and cement paste, steel and concrete, and new and old concrete were reviewed in this paper. In general, it can be concluded that these interfaces exhibit similar microstructural characteristics and are considered as weak zones in concrete in terms of bond strength. Consequently, cracks tend to form within this zone, providing a direct path for the ingress of aggressive agents into concrete. Researchers have attempted several methods to improve the quality of these interfaces. Such information is important for understanding the mechanical properties and durability as well as how it might influence the long-term performance of concrete structures.

\section{REFERENCES}

Al Khalaf, M. N., \& Page, C. L. (1979). Steel/mortar interfaces: Microstructural features and mode of failure. Cement and Concrete Research, 9(2), 197-207. https://doi.org/10.1016/0008-8846(79)90026-7

Angst, U. M., Geiker, M. R., Michel, A., Gehlen, C., Wong, H., Isgor, O. B., Elsener, B., Hansson, C. M., François, R., Hornbostel, K., Polder, R., Alonso, M. C., Sanchez, M., Correia, M. J., Criado, M., Sagüés, A., \& Buenfeld, N. (2017). The steel-concrete interface. Materials and Structures/Materiaux et Constructions, 50(2). https://doi.org/10.1617/s11527-017-1010-1

Bentur, A., \& Odler, I. (1996). Development and nature of interfacial microstructure. In J. . Maso (Ed.), Interfacial Transition Zone in Concrete (p. 18). E \& FN SPON. https://doi.org/10.1016/1065-7355(95)90037-3

Bentur, Arnon, \& Cohen, M. D. (1987). Effect of Condensed Silica Fume on the Microstructure of the Interfacial Zone in Portland Cement Mortars. Journal of the American Ceramic Society, 70(10), 738-743. https://doi.org/10.1111/j.1151-2916.1987.tb04873.x

Bentz, D. P., \& Garboczi, E. J. (1991). Simulation studies of the effects of mineral admixtures on the cement paste-aggregate interfacial zone. ACI Materials Journal, 88(5), 518-529.

Beushausen, H., \& Alexander, M. G. (2008). Bond strength development between concretes of different ages. Magazine of Concrete Research, 60(1), 65-74. https://doi.org/10.1680/macr.2007.00108

Breton, D., Carles-Gibergues, A., Ballivy, G., \& Grandet, J. (1993). Contribution to the formation mechanism of the transition zone between rock-cement paste. Cement and 
Concrete Research, 23(2), 335-346. https://doi.org/10.1016/0008-8846(93)90099-U

Carles-Gibergues, A., Saucier, F., Grandet, J., \& Pigeon, M. (1993). New-to-old concrete bonding: Influence of sulfates type of new concrete on interface microstructure. Cement and Concrete Research, 23(2), 431-441. https://doi.org/10.1016/0008-8846(93)90108-L

Castel, A., Vidal, T., Viriyametanont, K., \& François, R. (2006). Effect of reinforcing bar orientation and location on bond with self-consolidating concrete. ACI Structural Journal, 103(4), 559-567. https://doi.org/10.14359/16432

Cheng-yi, H., \& Feldman, R. F. (1985). Influence of silica fume on the microstructural development in cement mortars. Cement and Concrete Research, 15(2), 285-294. https://doi.org/10.1016/0008-8846(85)90040-7

Chung, D. D. L. (2001). Interface engineering for cement-matrix composites. Composite Interfaces, 8(1), 67-81. https://doi.org/10.1163/15685540052543665

Cohen, M. D., Goldman, A., \& Chen, W. F. (1994). The role of silica fume in mortar: Transition zone versus bulk paste modification. Cement and Concrete Research, 24(1), 95-98. https://doi.org/10.1016/0008-8846(94)90089-2

Courard, L. (2000). Parametric study for the creation of the interface between concrete and repair products. Materials and Structures/Materiaux et Constructions, 33(1), 65-72. https://doi.org/10.1007/bf02481698

Delagrave, A., Bigas, J. P., Ollivier, J. P., Marchand, J., \& Pigeon, M. (1997). Influence of the interfacial zone on the chloride diffusivity of mortars. Advanced Cement Based Materials, 5(3-4), 86-92. https://doi.org/10.1016/S1065-7355(96)00008-9

Diamond, S., \& Huang, J. (2001). The ITZ in concrete - A different view based on image analysis and SEM observations. Cement and Concrete Composites, 23(2-3), 179-188. https://doi.org/10.1016/S0958-9465(00)00065-2

Diamond, Sidney. (2004). The microstructure of cement paste and concrete - A visual primer. Cement and Concrete Composites, 26(8), 919-933. https://doi.org/10.1016/j.cemconcomp.2004.02.028

Emberson, N. K., \& Mays, G. C. (1990). Significance of property mismatch in the patch repair of structural concrete Part 1: Properties of repair systems. Magazine of Concrete Research, 42(152), 147-160. https://doi.org/10.1680/macr.1990.42.152.147

Emmons, P. H., \& Vaysburd, A. M. (1994). Factors affecting the durability of concrete repair: the contractor's viewpoint. Construction and Building Materials, 8(1), 5-16. https://doi.org/10.1016/0950-0618(94)90003-5

Farran, J. (1996). Introduction: The transition zone - discovery and development. In J. . Maso (Ed.), Interfacial Transition Zone in Concrete. E\&FN Spon.

Garboczi, E. J., \& Bentz, D. P. (1991). Digital simulation of the aggregate - cement paste interfacial zone in concrete. Journal of Materials Research, 6(1), 196-201. https://doi.org/10.1557/JMR.1991.0196

Gjorv, O. E., Monteiro, P. J. M., \& Mehta, P. K. (1990). Effect of condensed silica fume on the steel-concrete bond. ACI Materials Journal, 87(6), 573-580. https://doi.org/10.14359/2527

Hassan, K. E., Brooks, J. J., \& Al-Alawi, L. (2001). Compatibility of repair mortars with concrete in a hot-dry environment. Cement and Concrete Composites, 23(1), 93-101. https://doi.org/10.1016/S0958-9465(00)00073-1

Horne, A. T., Richardson, I. G., \& Brydson, R. M. D. (2007). Quantitative analysis of the microstructure of interfaces in steel reinforced concrete. Cement and Concrete Research, 37(12), 1613-1623. https://doi.org/10.1016/j.cemconres.2007.08.026

Hoshino, M. (1989). Relationship between bleeding, coarse aggregate, and specimen height of concrete. ACI Materials Journal, 86(2), 185-190. https://doi.org/10.14359/2252

Hsu, T. T. C., \& Slate, F. O. (1963). Tensile Bond Strength Between Aggregate and Cement 
Paste or Mortar. ACI Journal Proceedings, 60(4). https://doi.org/10.14359/7863

Júlio, E. N. B. S., Branco, F. A. B., \& Silva, V. D. (2004). Concrete-to-concrete bond strength. Influence of the roughness of the substrate surface. Construction and Building Materials, 18(9), 675-681. https://doi.org/10.1016/j.conbuildmat.2004.04.023

Júlio, E. N. B. S., Branco, F. A. B., Silva, V. D., \& Lourenço, J. F. (2006). Influence of added concrete compressive strength on adhesion to an existing concrete substrate. Building and Environment, 41(12), 1934-1939. https://doi.org/10.1016/j.buildenv.2005.06.023

Khayat, K. H. (1998). Use of viscosity-modifying admixture to reduce top-bar effect of anchored bars cast with fluid concrete. ACI Materials Journal, 95(2), 158-167. https://doi.org/10.14359/361

Kjellsen, K. O., Wallevik, O. H., \& Fjällberg, L. (1998). Microstructure and microchemistry of the paste-aggregate interfacial transition zone of high-performance concrete. Advances in Cement Research, 10(1), 33-40. https://doi.org/10.1680/adcr.1998.10.1.33

Larbi, J. A. (1993). Microstructure of the interfacial zone around aggregate particles in concrete. Heron.

Li, Z., Xu, M., \& Chui, N. C. (1998). Enhancement of rebar (smooth surface) - Concrete bond properties by matrix modification and surface coatings. Magazine of Concrete Research, 50(1), 49-57. https://doi.org/10.1680/macr.1998.50.1.49

Luković, M., Šavija, B., Dong, H., Schlangen, E., \& Ye, G. (2014). Micromechanical study of the interface properties in concrete repair systems. Journal of Advanced Concrete Technology, 12(9), 320-339. https://doi.org/10.3151/jact.12.320

Momayez, A., Ramezanianpour, A. A., Rajaie, H., \& Ehsani, M. R. (2004). Bi-surface shear test for evaluating bond between existing and new concrete. In ACI Materials Journal (Vol. 101, Issue 2, pp. 99-106). https://doi.org/10.14359/13045

Mondai, P., Shah, S. R., \& Marks, L. D. (2008). Nanoscale characterization of cementitious materials. ACI Materials Journal, 105(2), 174-179. https://doi.org/10.1007/978-3-319$17088-65$

Monteiro, P. J. M., Gjorv, O. E., \& Mehta, P. K. (1985). Microstructure of the steel-cement paste interface in the presence of chloride. Cement and Concrete Research, 15(5), 781784. https://doi.org/10.1016/0008-8846(85)90143-7

Monteiro, P. J. M., Maso, J. C., \& Ollivier, J. P. (1985). The aggregate-mortar interface. Cement and Concrete Research, 15(6), 953-958. https://doi.org/10.1016/00088846(85)90084-5

Morgan, D. R. (1996). Compatibility of concrete repair materials and systems. Construction and Building Materials, 10(1 SPEC. ISS.), 57-67. https://doi.org/10.1016/09500618(95)00060-7

Otsuki, N., Hisada, M., Diola, N. B., \& Uddin, T. (1998). Experimental study on interfacial transition zones in reinforced concrete. Doboku Gakkai Ronbunshu, 592, 155-167. https://doi.org/10.2208/jscej.1998.592_155

Pigeon, M., \& Saucier, F. (1992). Durability of repaired concrete structures. International Symposium on Advances in Concrete Technology, 741-773.

Ping, X., \& Beaudoin, J. J. (1992). Effects of transition zone microstructure on bond strength of aggregate-portland cement paste interfaces. Cement and Concrete Research, 22(1), 23-26. https://doi.org/10.1016/0008-8846(92)90132-F

Scrivener, K. L., Pratt, P. L., \& Bentur, A. (1988). Quantitative characterization of the transition zone in high strength concretes. Advances in Cement Research, 1(4), 230-237. https://doi.org/10.1680/adcr.1988.1.4.230

Scrivener, Karen L., Crumbie, A. K., \& Laugesen, P. (2004). The interfacial transition zone (ITZ) between cement paste and aggregate in concrete. Interface Science, 12(4), 411-421. https://doi.org/10.1023/B:INTS.0000042339.92990.4c 
Snyder, K. A., Bentz, D. P., \& Garboczi, E. J. (1992). Interfacial zone percolation in cementaggregate composites. In Interfaces in Cementitious Composites (p. 27). E \& FN SPON.

Soylev, T. A., \& François, R. (2003). Quality of steel-concrete interface and corrosion of reinforcing steel. Cement and Concrete Research, 33(9), 1407-1415. https://doi.org/10.1016/S0008-8846(03)00087-5

Tasong, W. A., Lynsdale, C. J., \& Cripps, J. C. (1999). Aggregate-cement paste interface: Part I. Influence of aggregate geochemistry. Cement and Concrete Research, 29(7), 10191025. https://doi.org/10.1016/S0008-8846(99)00086-1

Tayeh, B. A., Abu Bakar, B. H., \& Megat Johari, M. A. (2013). Characterization of the interfacial bond between old concrete substrate and ultra high performance fiber concrete repair composite. Materials and Structures/Materiaux et Constructions, 46(5), 743-753. https://doi.org/10.1617/s11527-012-9931-1

Wall, J. S., \& Shrive, N. G. (1988). Factors Affecting Bond Between New and Old Concrete. ACI Materials Journal, 85(2), 117-125. https://doi.org/10.14359/2329

Xie, H. C., Li, G. Y., \& Xiong, G. J. (2002). Microstructure model of the interfacial zone between fresh and old concrete. Journal Wuhan University of Technology, Materials Science Edition, 17(4), 64-68. https://doi.org/10.1007/bf02838421

Yue, L., \& Shuguang, H. (2001). The microstructure of the interfacial transition zone between steel and cement paste. Cement and Concrete Research, 31(3), 385-388. https://doi.org/10.1016/S0008-8846(01)00452-5

Zampini, D., Jennings, H. M., \& Shah, S. P. (1995). Characterization of the paste-aggregate interfacial transition zone surface roughness and its relationship to the fracture toughness of concrete. Journal of Materials Science, 30(12), 3149-3154. https://doi.org/10.1007/BF01209230

Zimbelmann, R. (1985). A contribution to the problem of cement-aggregate bond. Cement and Concrete Research, 15(5), 801-808. https://doi.org/10.1016/0008-8846(85)90146-2

Zimbelmann, R. (1987). A method for strengthening the bond between cement stone and aggregates. Cement and Concrete Research, 17(4), 651-660. https://doi.org/10.1016/00088846(87)90138-4 